\title{
Historical and future changes in air pollutants from CMIP6 models
}

Steven T. Turnock ${ }^{1}$, Robert J. Allen ${ }^{2}$, Martin Andrews ${ }^{1}$, Susanne E. Bauer ${ }^{3,4}$, Louisa Emmons ${ }^{5}$, Peter Good $^{1}$, Larry Horowitz ${ }^{6}$, Martine Michou ${ }^{7}$, Pierre Nabat ${ }^{7}$, Vaishali Naik ${ }^{6}$, David Neubauer ${ }^{8}$, Fiona M. O’Connor $^{1}$, Dirk Olivié ${ }^{9}$, Michael Schulz ${ }^{9}$, Alistair Sellar ${ }^{1}$, Toshihiko Takemura ${ }^{10}$, Simone Tilmes ${ }^{5}$, 5 Kostas Tsigaridis ${ }^{3,4}$, Tongwen $\mathrm{Wu}^{11}$, Jie Zhang ${ }^{11}$

${ }^{1}$ Met Office Hadley Centre, Exeter, UK

${ }^{2}$ Department of Earth and Planetary Sciences, University of California Riverside, Riverside, California, USA

${ }^{3}$ Center for Climate Systems Research, Columbia University, New York, NY, USA

${ }^{4}$ NASA Goddard Institute for Space Studies, New York, NY, USA

$10{ }^{5}$ Atmospheric Chemistry Observations and Modelling Lab, National Center for Atmospheric Research, Boulder, CO, USA

${ }^{6}$ DOC/NOAA/OAR/Geophysical Fluid Dynamics Laboratory. Biogeochemistry, Atmospheric Chemistry, and Ecology Division, Princeton, USA

${ }^{7}$ Centre National de Recherches Météorologiques (CNRM), Université de Toulouse, Météo-France, CNRS, Toulouse, France ${ }^{8}$ Institute of Atmospheric and Climate Science, ETH Zurich, Zurich, Switzerland

$15{ }^{9}$ Division for Climate Modelling and Air Pollution, Norwegian Meteorological Institute, Oslo, Norway

${ }^{10}$ Research Institute for Applied Mechanics, Kyushu University, Fukuoka, Japan

${ }^{11}$ Beijing Climate Center, China Meteorological Administration, Beijing, China

Correspondence to: Steven Turnock (steven.turnock@metoffice.gov.uk)

\section{Supplementary Material}

\section{Contents}

Figure S1 - Definition of Regions

Figures S2-S6 - Seasonal mean surface $\mathrm{O}_{3}$ concentrations from individual CMIP6 models compared to observations

Figures S7-S11 - Annual mean PM 2.5 component concentrations in 2005-2014 across the individual CMIP6 models

Figure S12 - Annual and seasonal mean $\mathrm{PM}_{2.5} \mathrm{NO}_{3}$ component concentrations in 2005-2014 across the individual CMIP6

25 models that made the data available

Figure S13 - Regional surface temperature response across CMIP6 models for Tier 1 future scenarios

Figure S14 - Global plots of surface $\mathrm{O}_{3}$ response in ssp370 from 4 CMIP6 models

Figure S15 - Emissions of biogenic Volatile organic compounds across three CMIP6 models

Figure S16-S20 - Annual mean response of $\mathrm{PM}_{2.5}$ component concentrations in ssp370 across four individual CMIP6 models 


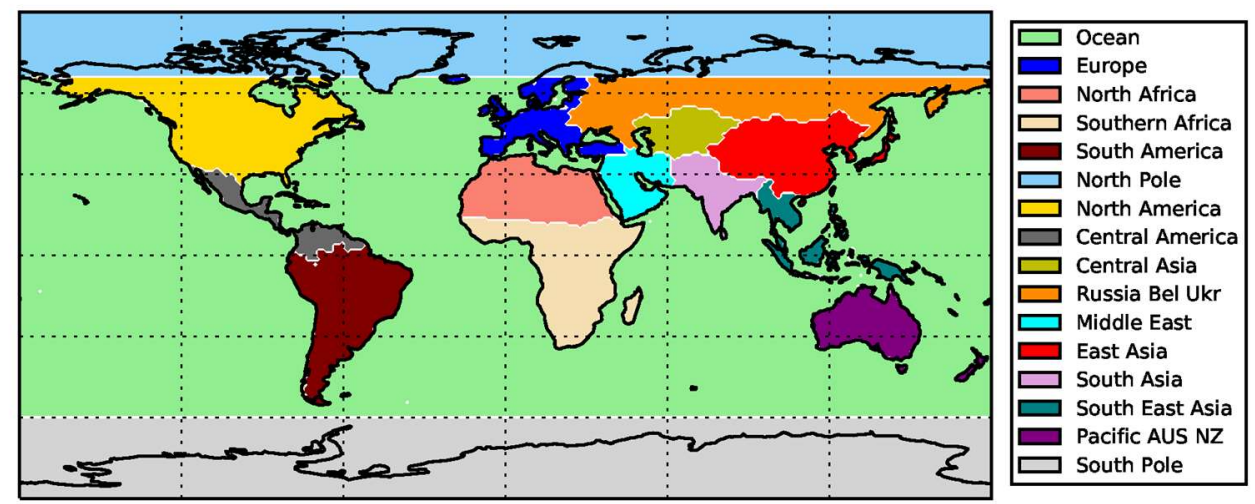

Figure S1 - Definition of regions used in the study, based on those used in Phase 2 of the Hemispheric Transport of Air Pollutants (HTAP2)

a) Surface $\mathrm{O}_{3}$ from UKESM1 in DJF

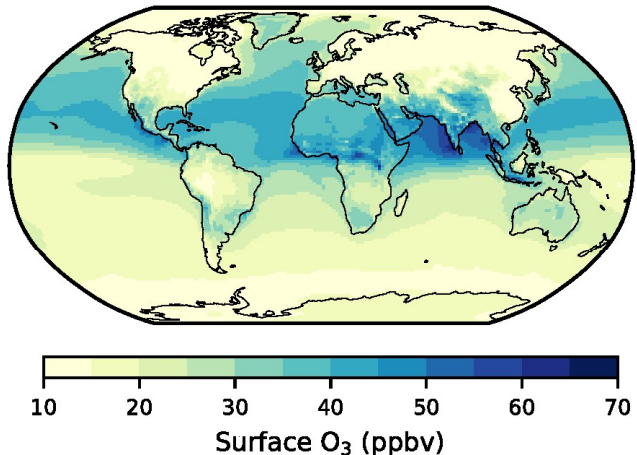

c) Surface $\mathrm{O}_{3}$ from UKESM1 in JJA

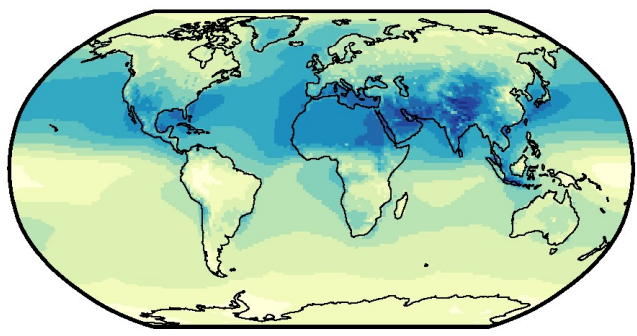

b) Surface $\mathrm{O}_{3}$ Bias from UKESM1 in DJF

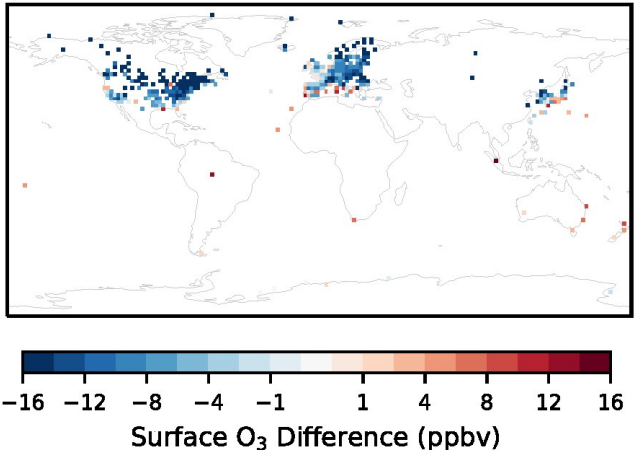

d) Surface $\mathrm{O}_{3}$ Bias from UKESM1 in JJA

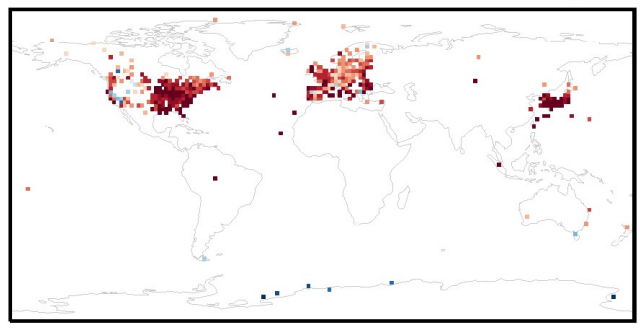

Figure S2 - Seasonal mean surface O3 concentrations from UKESM1 in a) December January, February (DJF) and c) June, July, August (JJA) over the 2005-2014 period. Difference between the UKESM1 mean and TOAR observations for b) DJF and d) JJA. 
a) Surface $\mathrm{O}_{3}$ from BCC-ESM1 in DJF

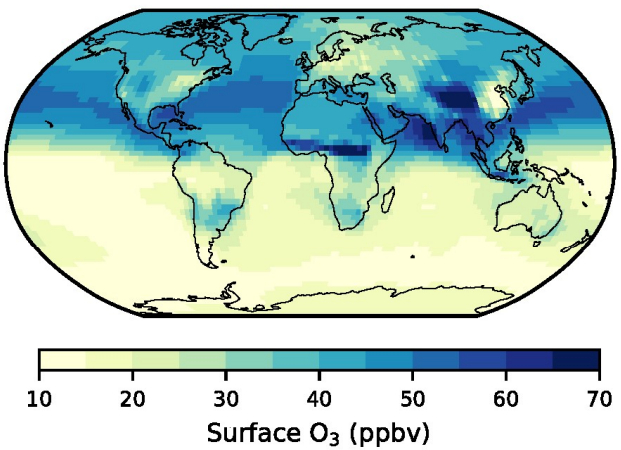

c) Surface $\mathrm{O}_{3}$ from BCC-ESM1 in JJA

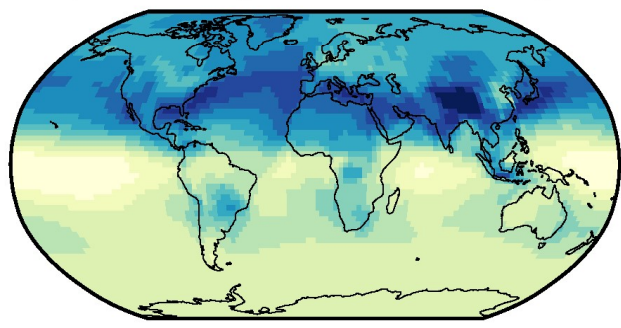

b) Surface $\mathrm{O}_{3}$ Bias from BCC-ESM1 in DJF

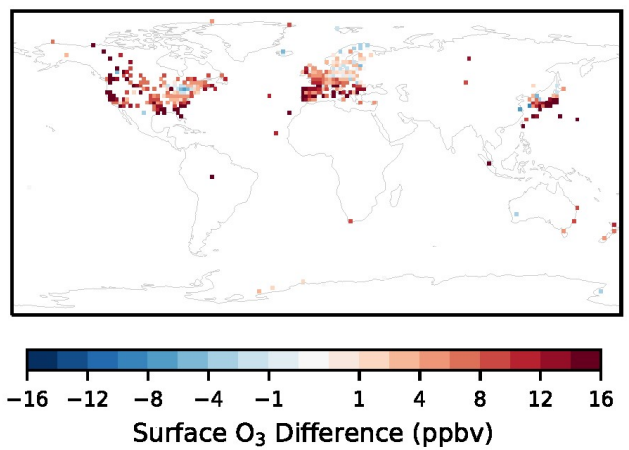

d) Surface $\mathrm{O}_{3}$ Bias from BCC-ESM1 in JJA

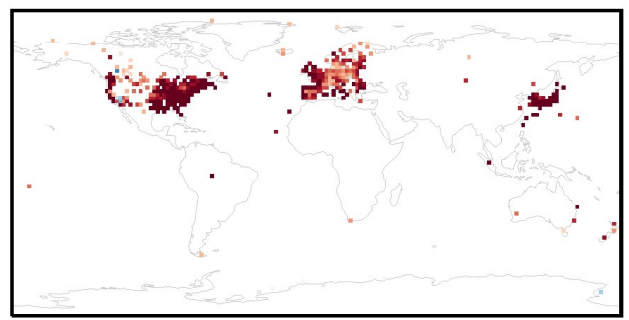

Figure S3 - Seasonal mean surface $\mathrm{O}_{3}$ concentrations from BCC-ESM1 in a) December January, February (DJF) and c) June, July, August (JJA) over the 2005-2014 period. Difference between the BCC-ESM1 mean and TOAR observations for b) DJF and d) JJA.

a) Surface $\mathrm{O}_{3}$ from CESM2 in DJF

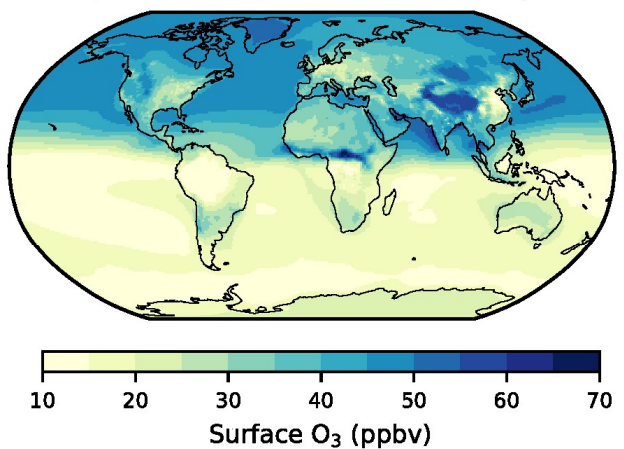

c) Surface $\mathrm{O}_{3}$ from CESM2 in JJA

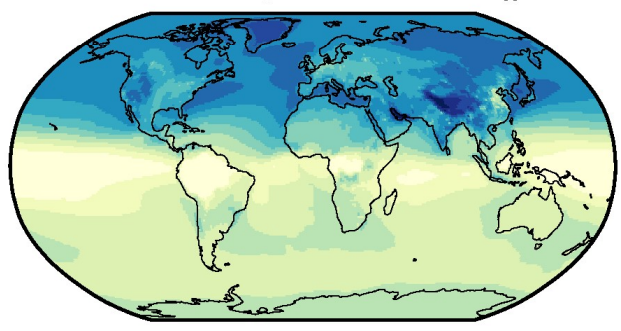

b) Surface $\mathrm{O}_{3}$ Bias from CESM2 in DJF

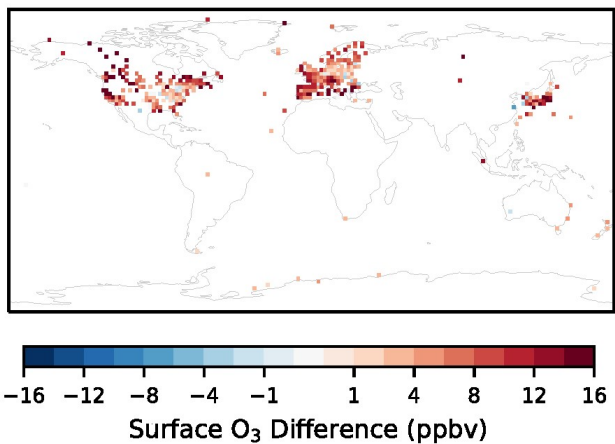

d) Surface $\mathrm{O}_{3}$ Bias from CESM2 in JJA

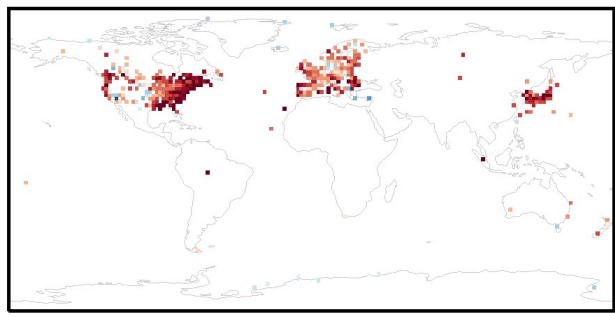

45 Figure S4 - Seasonal mean surface O3 concentrations from CESM2 in a) December January, February (DJF) and c) June, July, August (JJA) over the 2005-2014 period. Difference between the CESM2 mean and TOAR observations for b) DJF and d) JJA. 
a) Surface $\mathrm{O}_{3}$ from GFDL-ESM4 in DJF

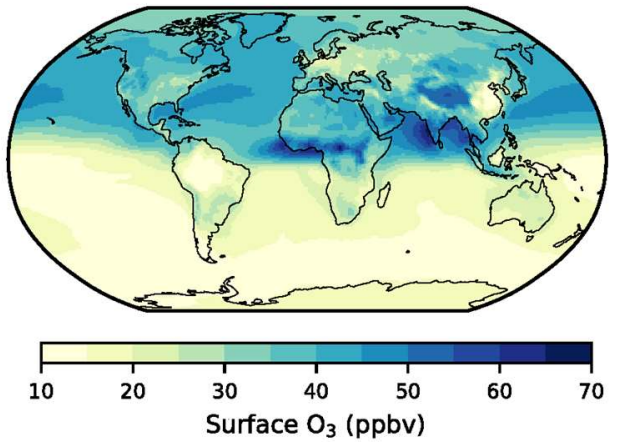

c) Surface $\mathrm{O}_{3}$ from GFDL-ESM4 in JJA

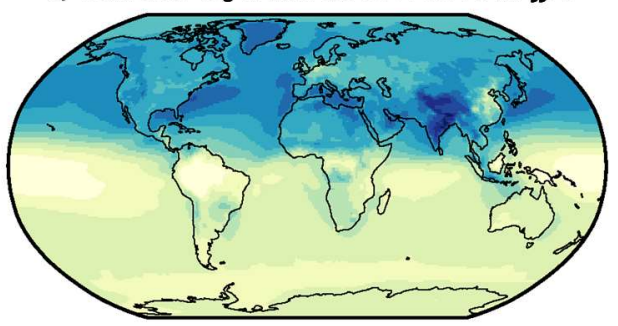

b) Surface $\mathrm{O}_{3}$ Bias from GFDL-ESM4 in DJF
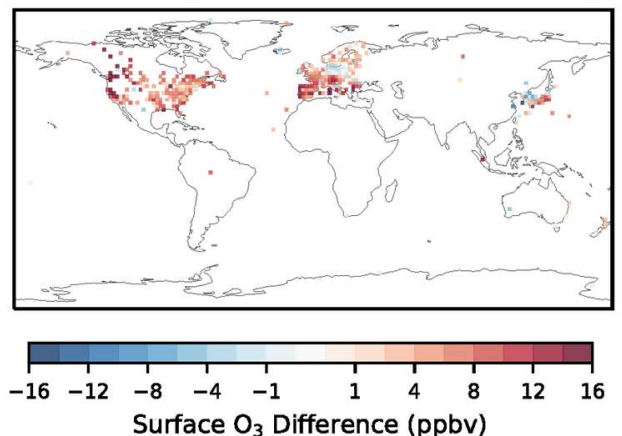

d) Surface $\mathrm{O}_{3}$ Bias from GFDL-ESM4 in JJA

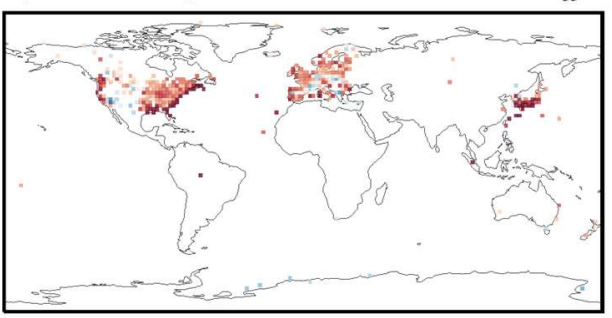

Figure S5 - Seasonal mean surface $O_{3}$ concentrations from GFDL-ESM4 in a) December January, February (DJF) and c) June, July, August (JJA) over the 2005-2014 period. Difference between the GFDL-ESM4 mean and TOAR observations for b) DJF and d) JJA.

a) Surface $\mathrm{O}_{3}$ from GISS-E2-1-H in DJF

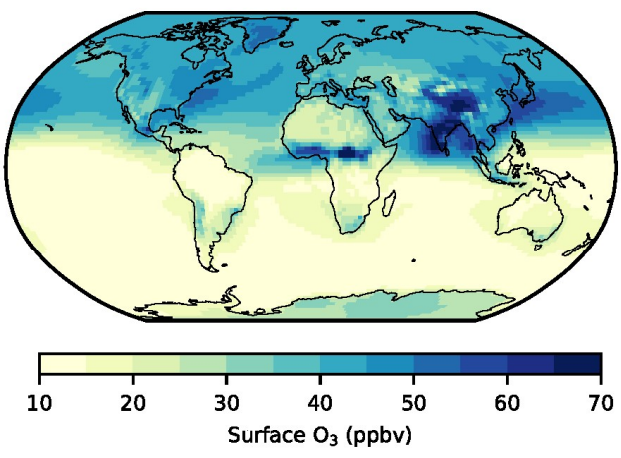

c) Surface $\mathrm{O}_{3}$ from GISS-E2-1-H in JJA

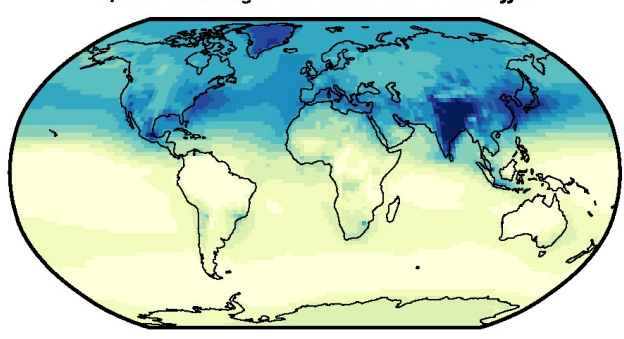

b) Surface $\mathrm{O}_{3}$ Bias from GISS-E2-1-H in DJF
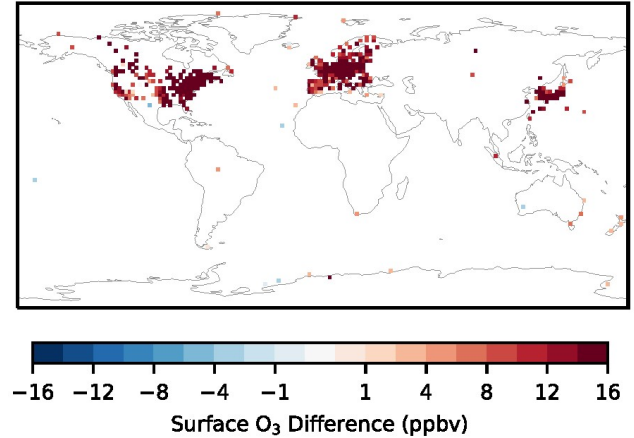

d) Surface $\mathrm{O}_{3}$ Bias from GISS-E2-1-H in JJA

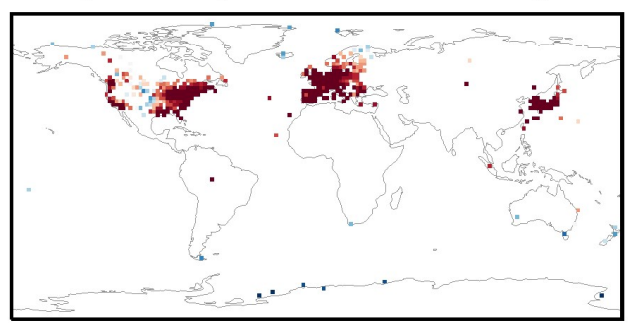

Figure S6 - Seasonal mean surface $\mathrm{O}_{3}$ concentrations from GISS-E2-1-H in a) December January, February (DJF) and c) June, July, August (JJA) over the 2005-2014 period. Difference between the GISS-E2-1-H mean and TOAR observations for b) DJF and d) JJA. 

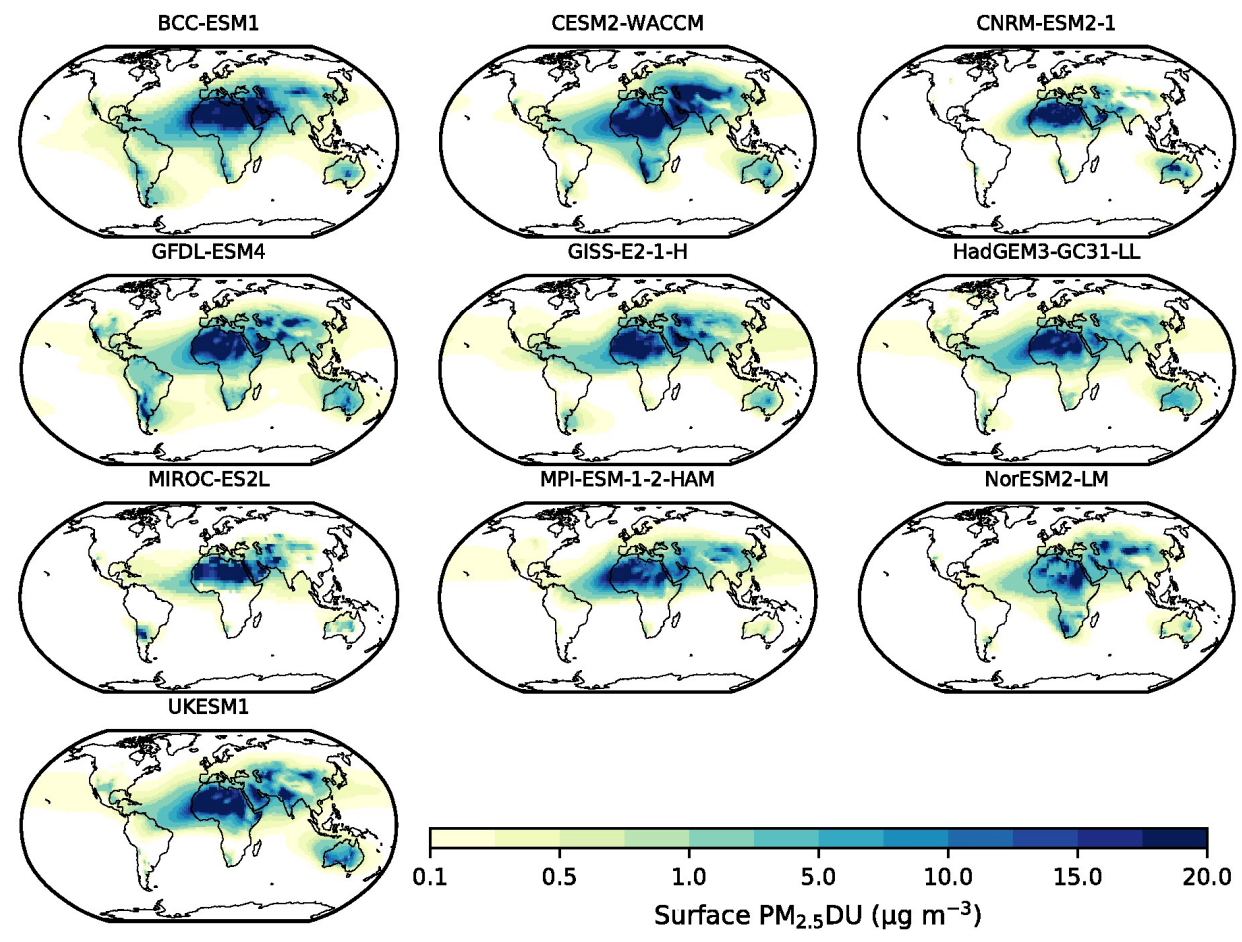

Figure S7 - Annual mean PM2.5 dust component calculated for each individual CMIP6 model over the period 2005-2014
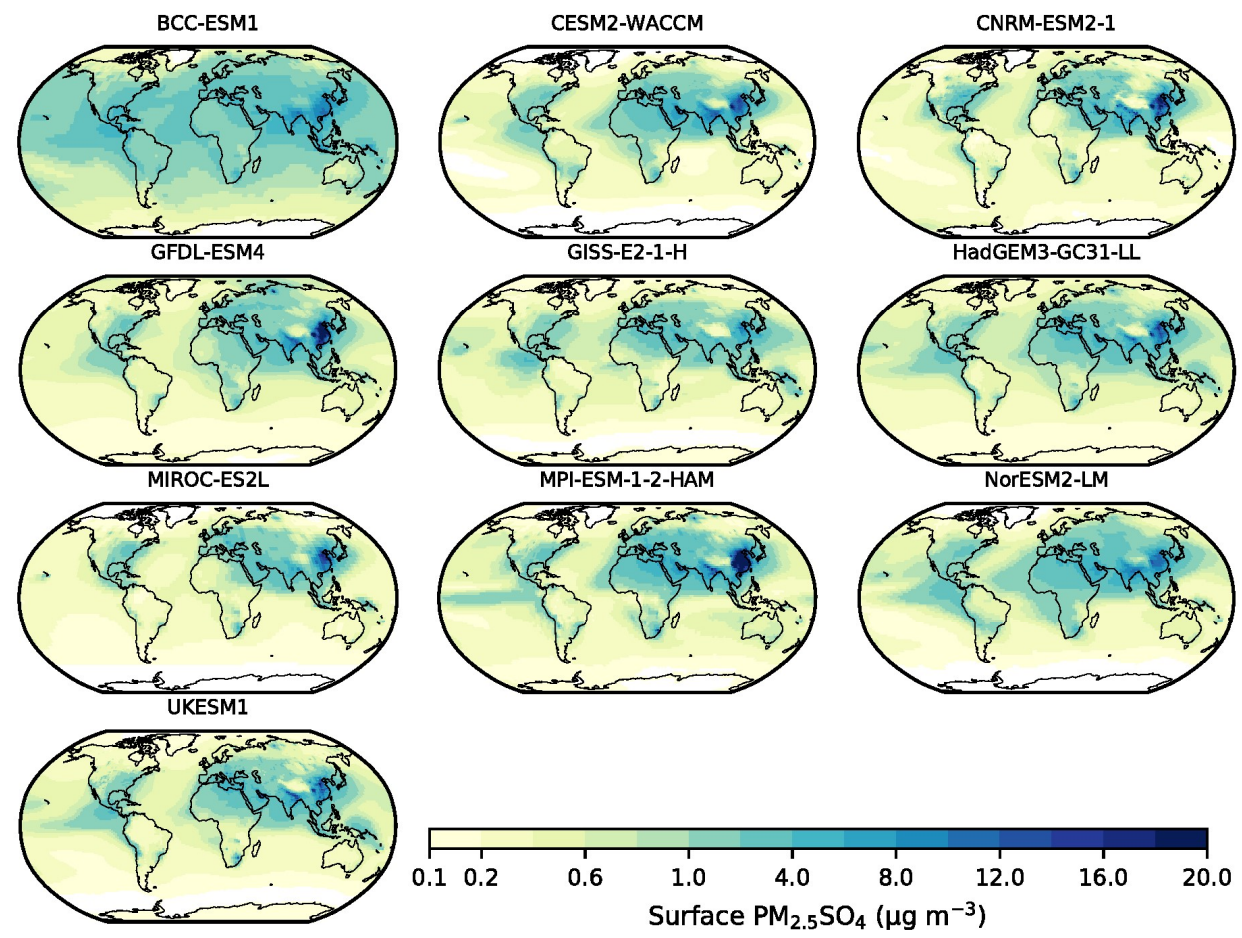

Figure S8 - Annual mean PM2.5 SO4 component calculated for each individual CMIP6 model over the period 2005-2014 

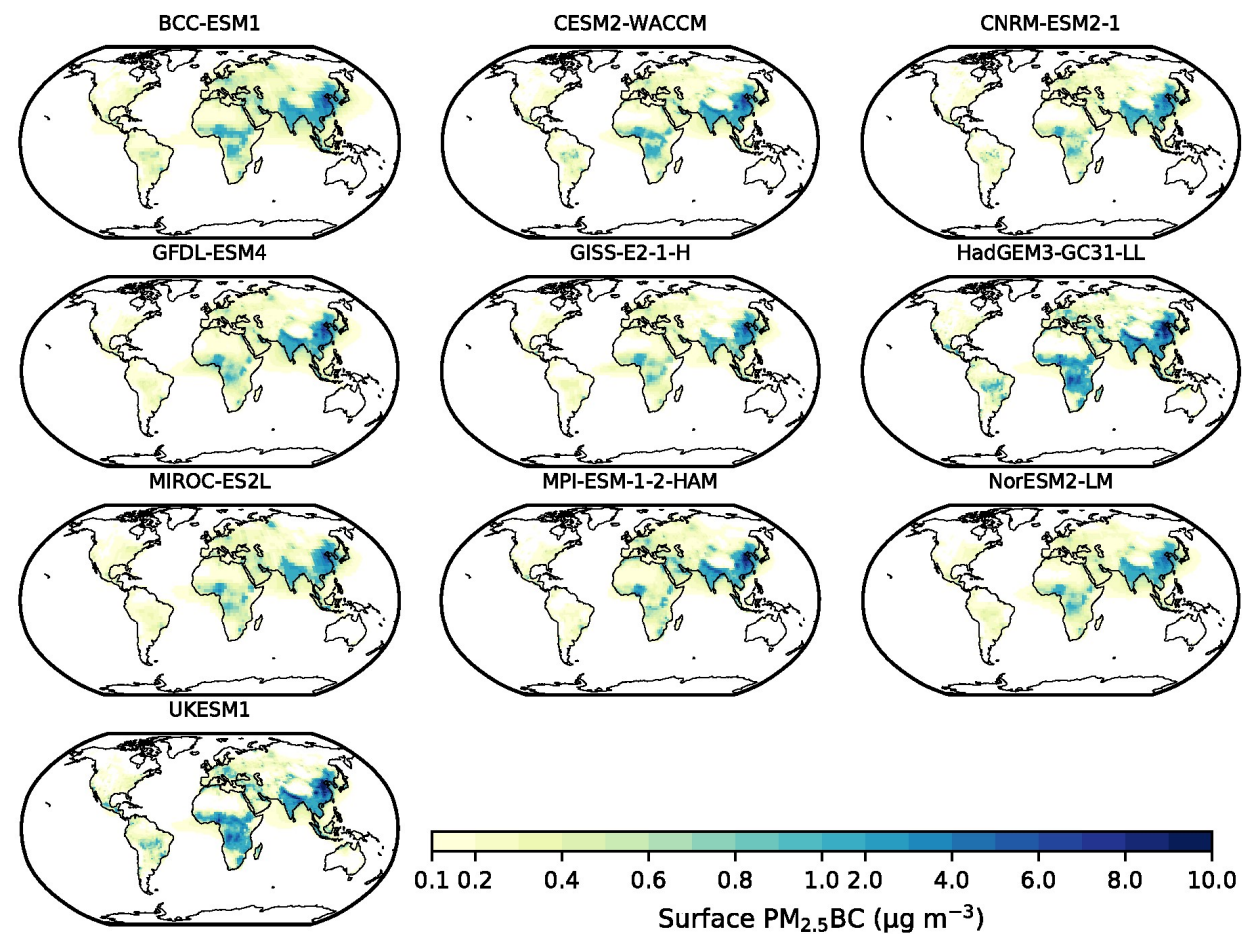

60

Figure S9 - Annual mean PM2.5 BC component calculated for each individual CMIP6 model over the period 2005-2014
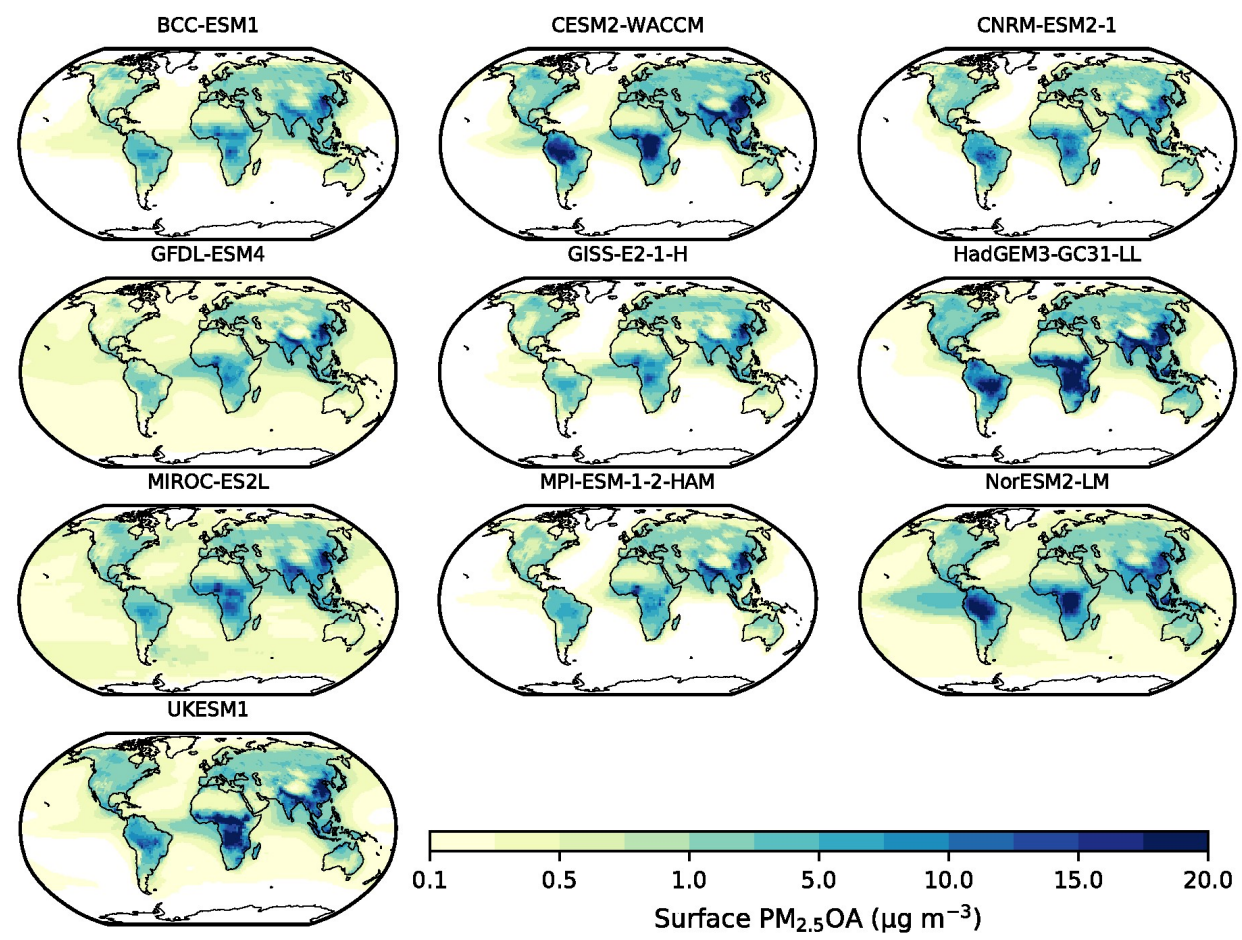

Figure S10 - Annual mean PM2.5 OA component calculated for each individual CMIP6 model over the period 2005-2014 


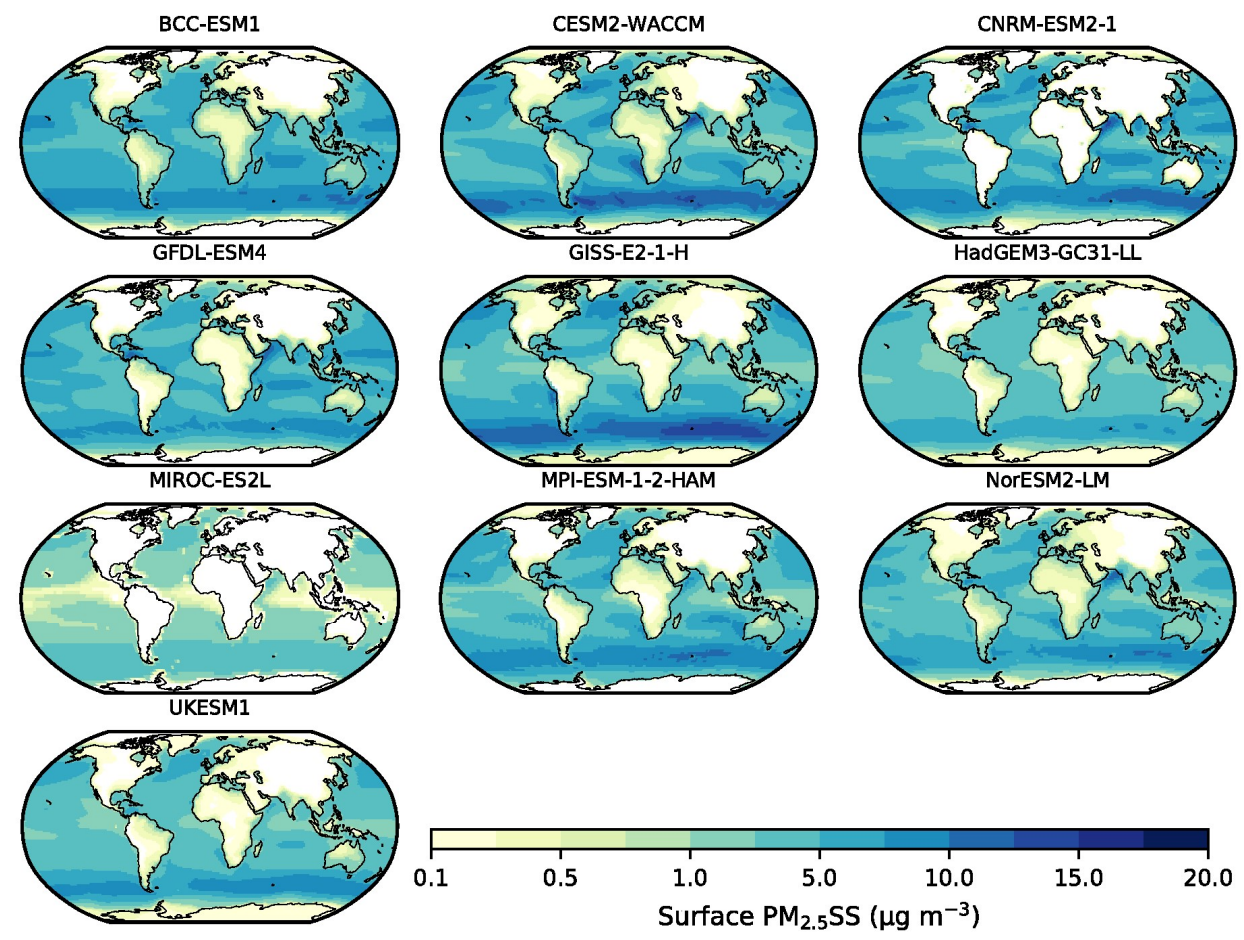

Figure S11 - Annual mean PM2.5 SS component calculated for each individual CMIP6 model over the period 2005-2014

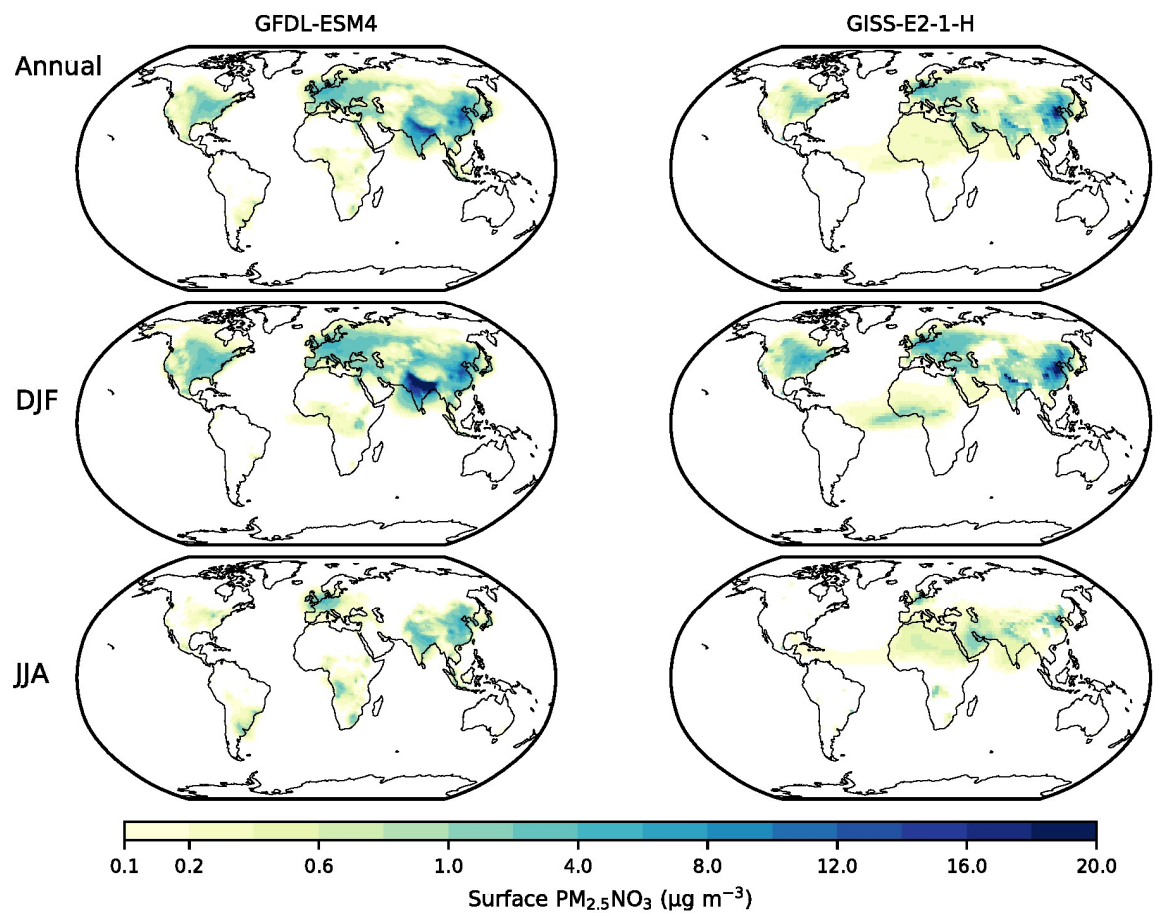

Figure S12 - Annual and seasonal mean PM2.5 $\mathrm{NO}_{3}$ (nitrate) component calculated for each individual CMIP6 model that made the data available over the period 2005-2014 

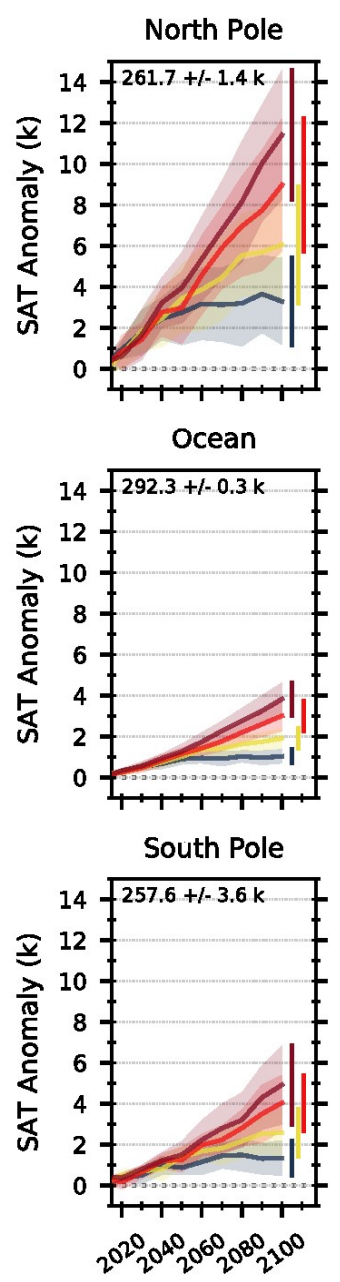

North America

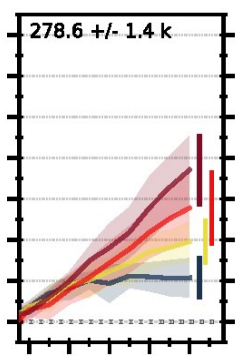

Europe

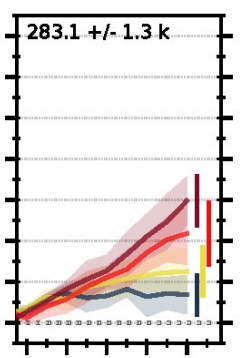

Central America

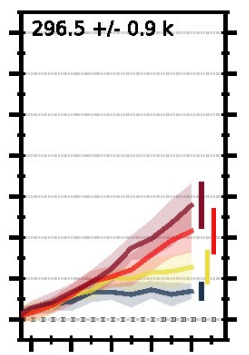

South America

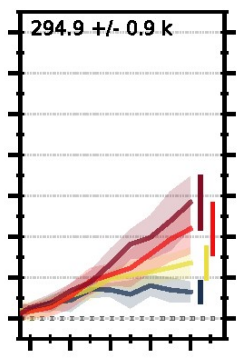

$2^{02}{ }_{2}^{0}{ }^{00}{ }^{0}{ }^{0}{ }_{2} 0^{80}{ }_{2} 0^{\circ}$

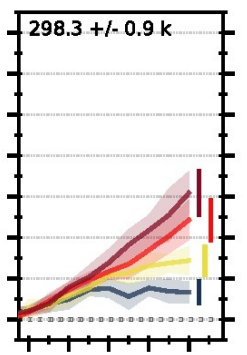

Southern Africa

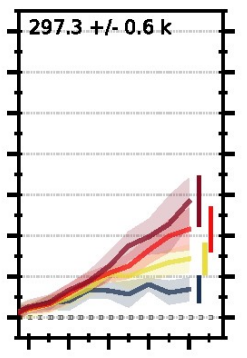

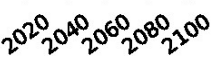

Rus Bel Ukr

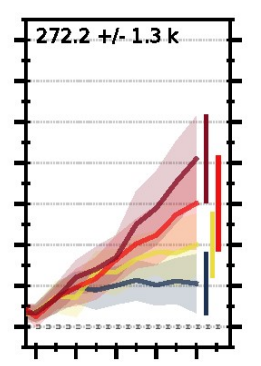

Middle East

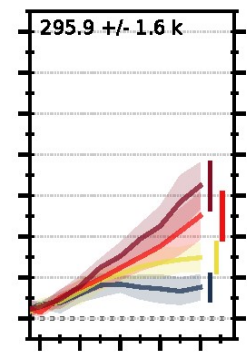

Pacific Aus NZ

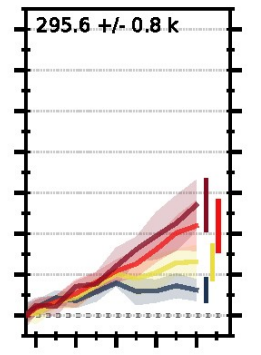

$2^{020}{ }_{2}^{00^{0}}{ }_{2} 0^{60}{ }_{2}{ }^{\circ}{ }_{2} 0^{\circ}$
Central Asia

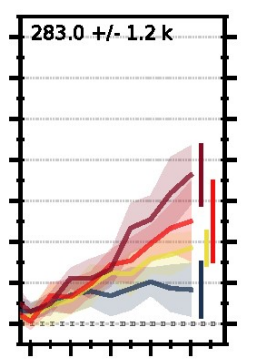

South Asia

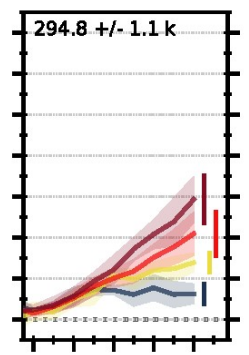

East Asia

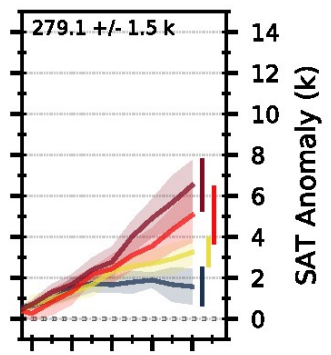

South East Asia

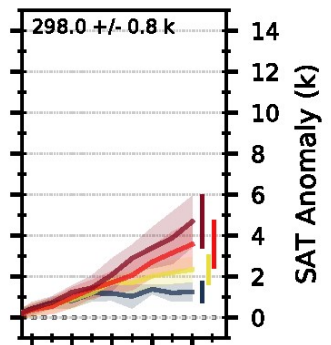

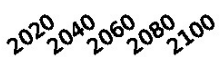

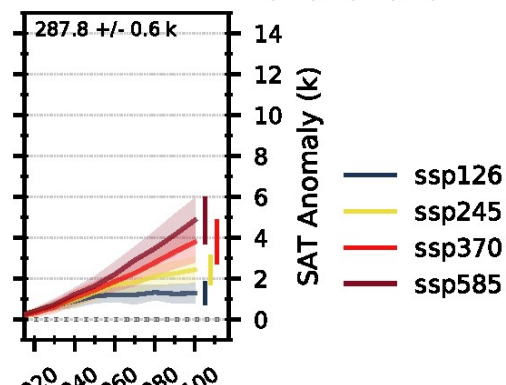

Figure S13 - Regional surface air temperature response across 5 CMIP6 models (CESM2-WACCM, CNRM-ESM2-1, GFDL-ESM4, MIROC-ES2L and UKESM1) for the Tier 1 future scenarios. Each line represents a multi-model mean across the region with shading representing the $+/-1$ standard deviation in the mean. The multi-model regional mean value ( $+/-1$ standard deviation) for the year 2005-2014 is shown in the top left corner of each panel. 


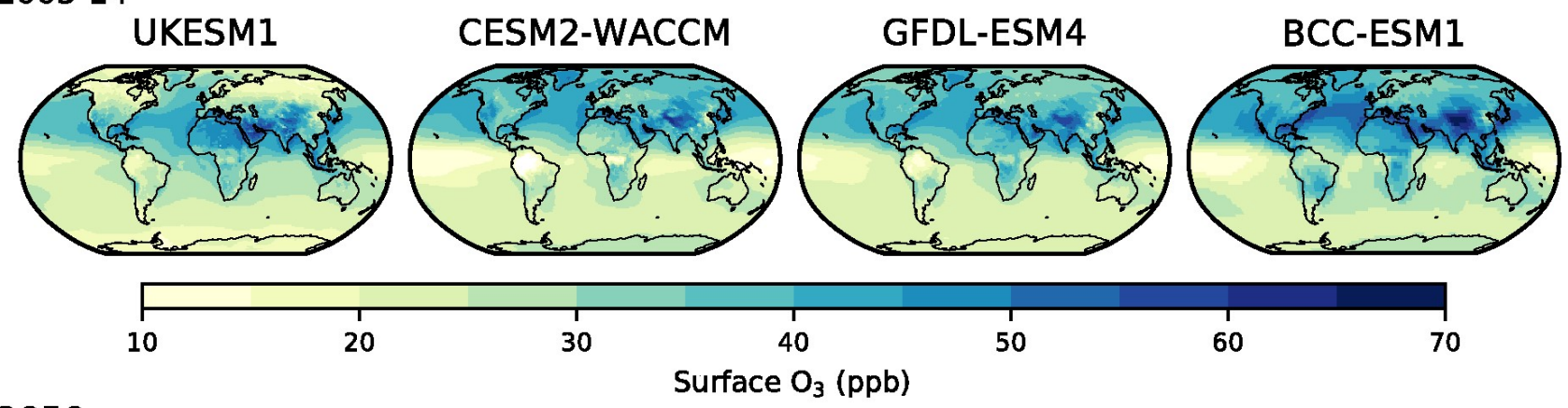

2050
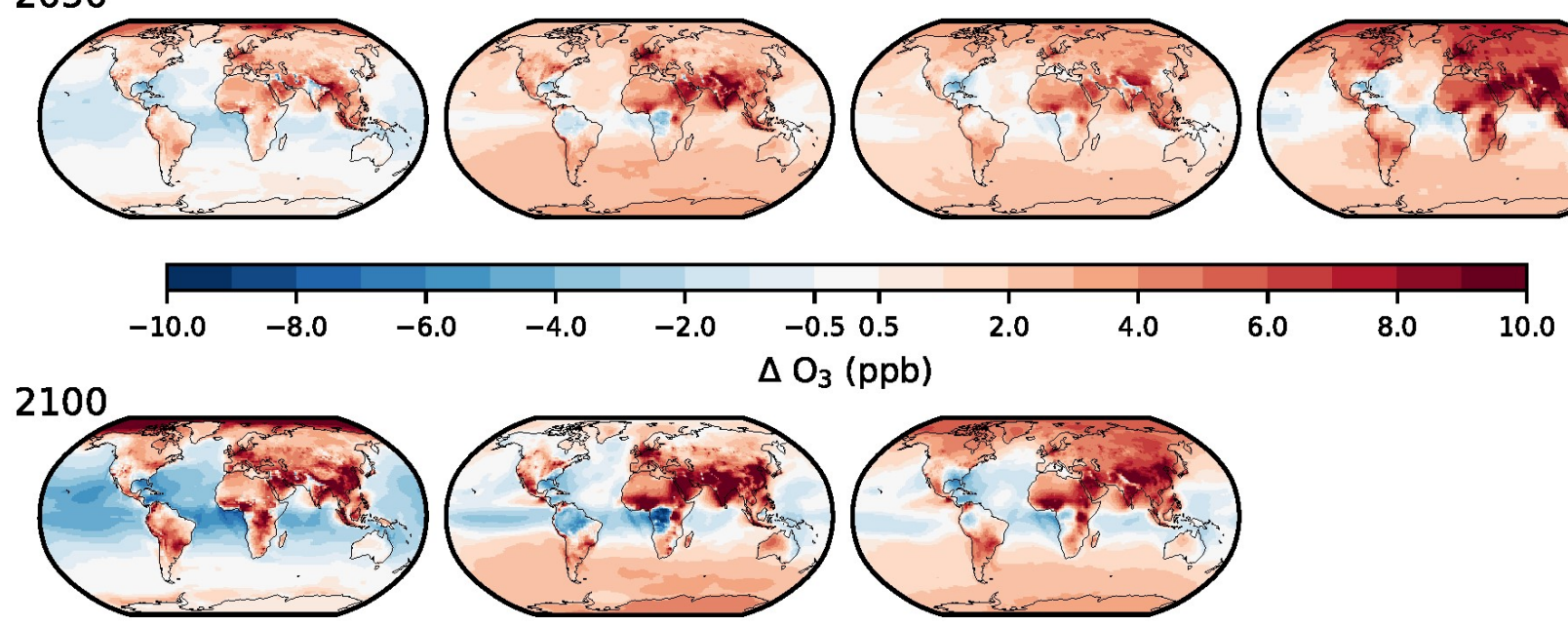

Figure S14 - Annual mean surface $\mathrm{O}_{3}$ concentrations and future response in ssp370 across four different CMIP6 models. Top row shows the 2005-2014 annual mean surface $O_{3}$ concentrations in each model from the historical simulations. Middle row shows the surface $\mathrm{O}_{3}$ response in 2050, relative to 2005-2014 mean, in each model for ssp370. Bottom row shows the same as the middle but for 2100. No data is presented in 2100 for BCC-ESM1 as data for ssp370 only extended out to 2055. 

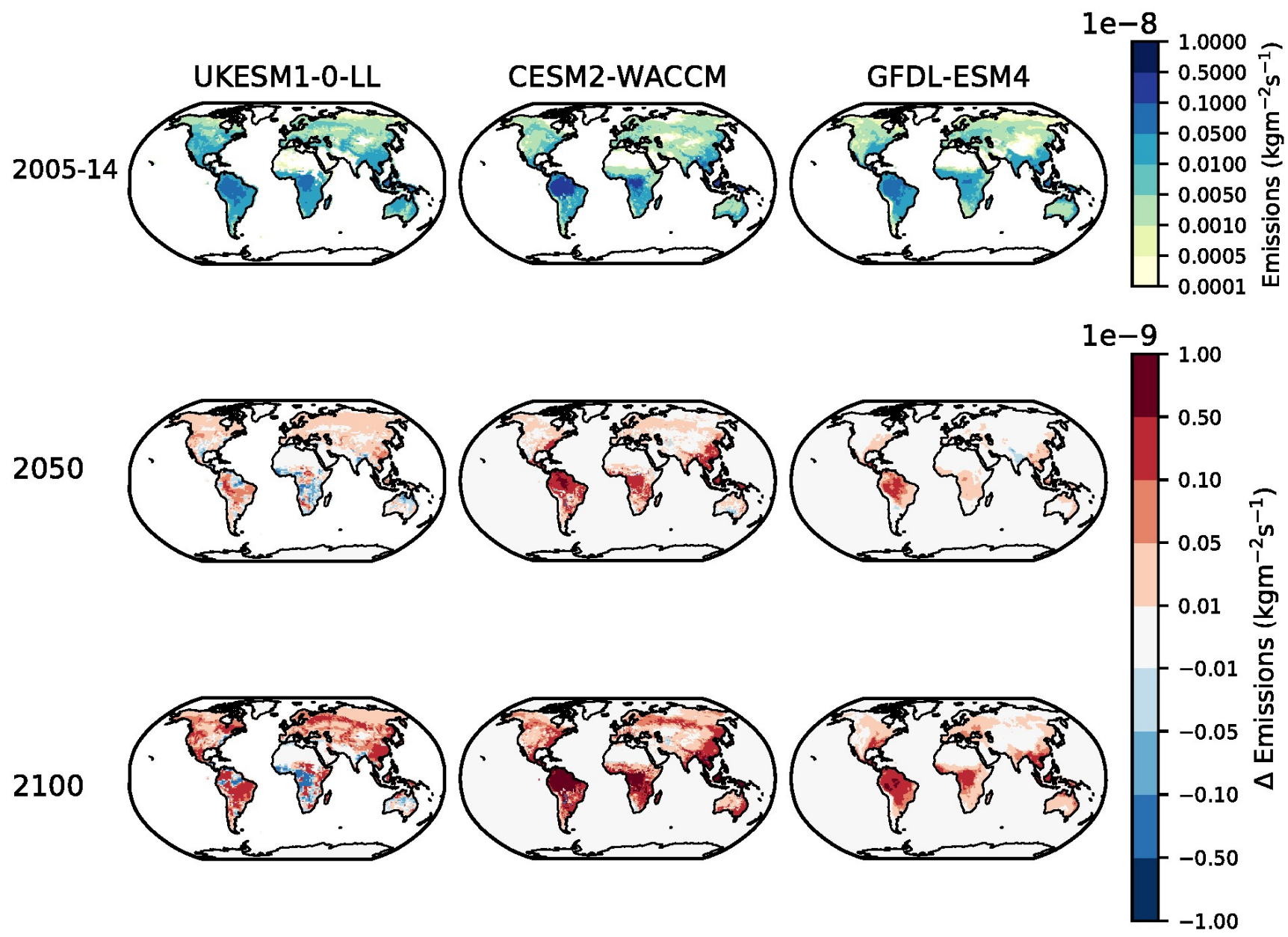

Figure S15 - Annual mean emissions of total biogenic volatile organic compounds across CMIP6 models. Top row shows the 2005802014 annual mean emissions in each model from the historical simulations. Middle row shows 2050 change in emissions, relative to 2005-2014 mean, in each model for ssp370. Bottom row shows the same as the middle but for 2100. 

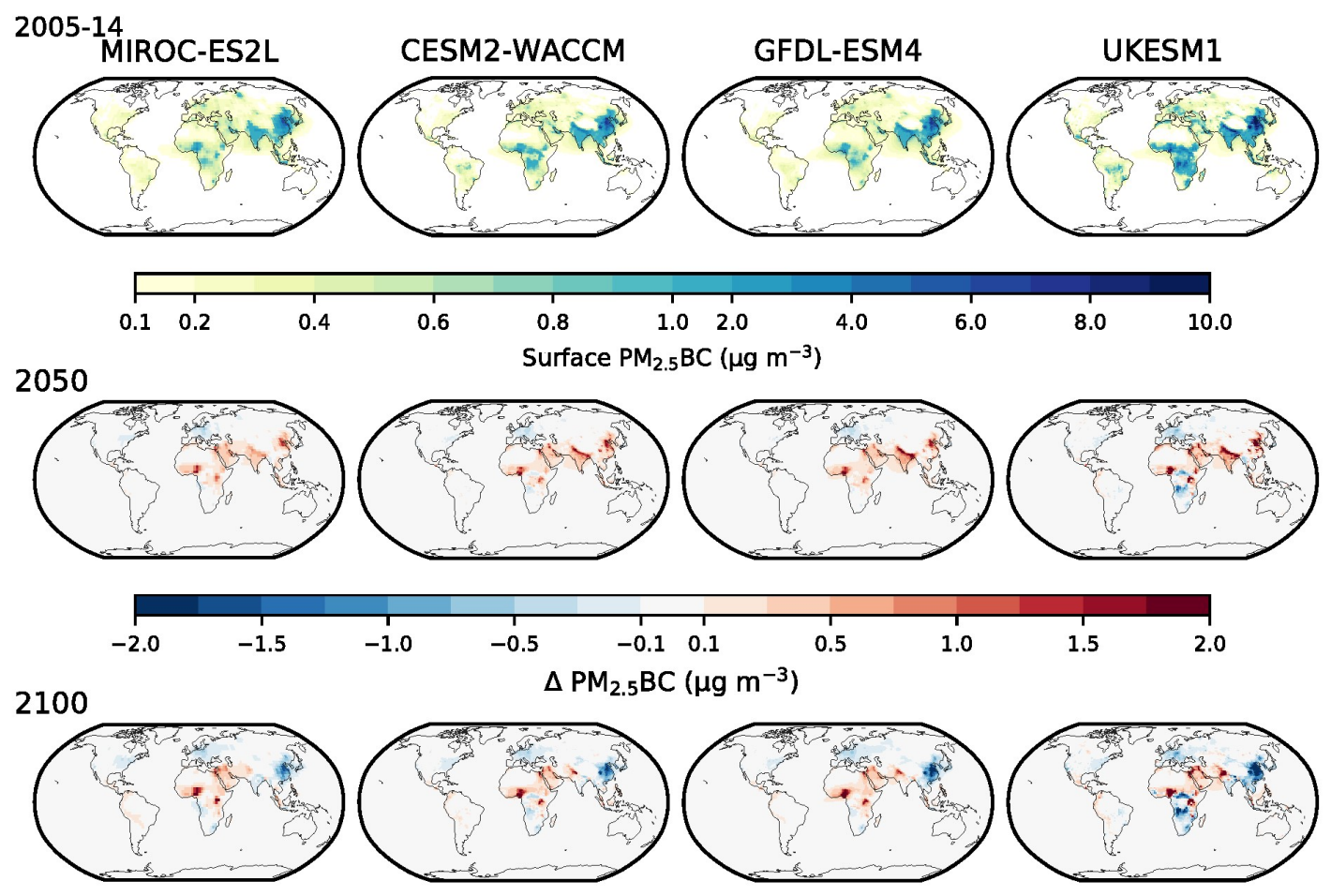

Figure S16 - Annual mean surface PM2.5 black carbon concentrations and future response in ssp370 across four different CMIP6 models. Top row shows the 2005-2014 annual mean surface $\mathbf{P M}_{2.5}$ black carbon concentrations in each model from the historical

85 simulations. Middle row shows the decadal mean surface PM2.5 black carbon response in 2050 (2045-2055), relative to 2005-2014 mean, in each model for ssp370. Bottom row shows the same as the middle but for 2095 (2090-2100). 

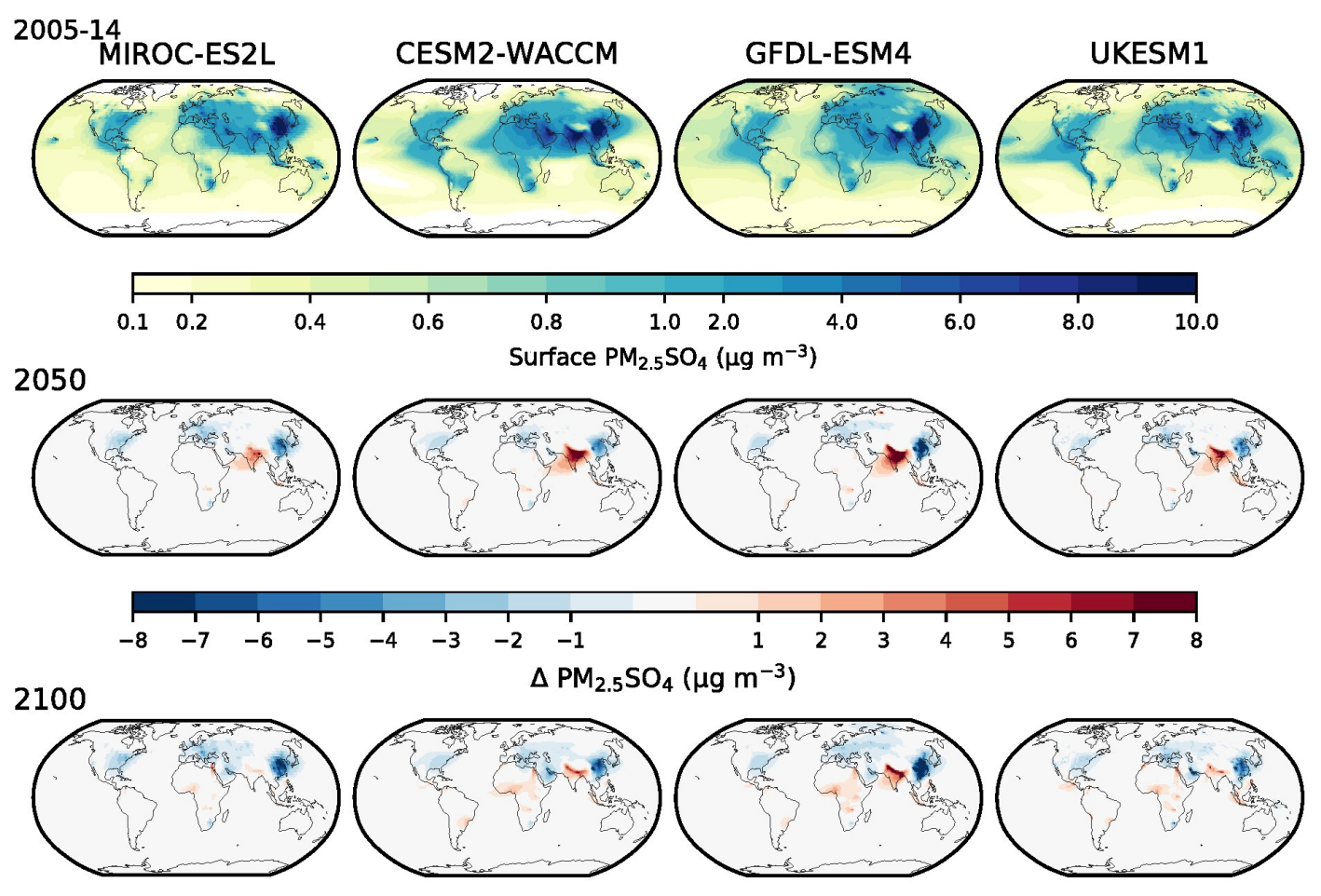

Figure S17 - same as Fig S16 but for $\mathrm{PM}_{2.5}$ sulphate

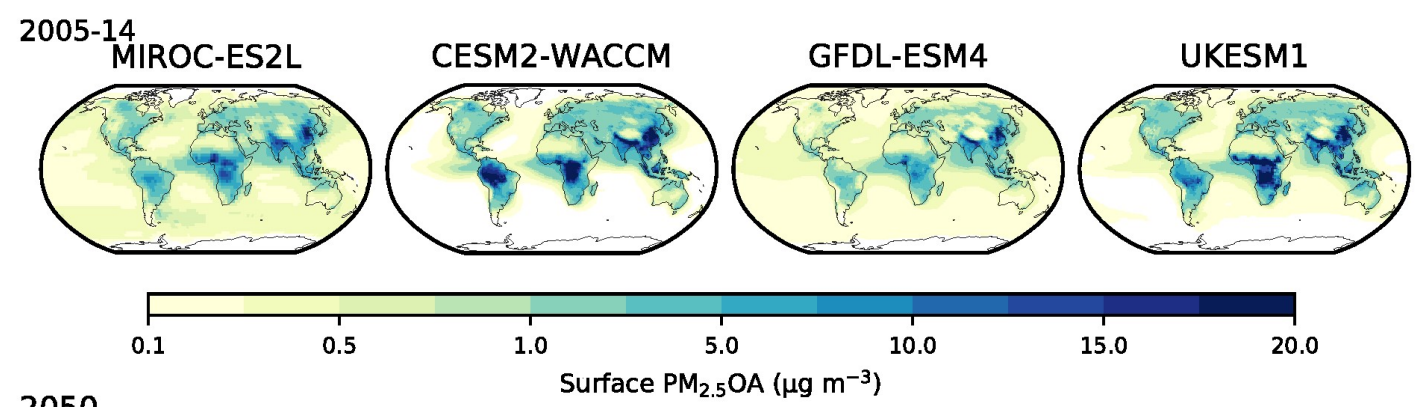

2050
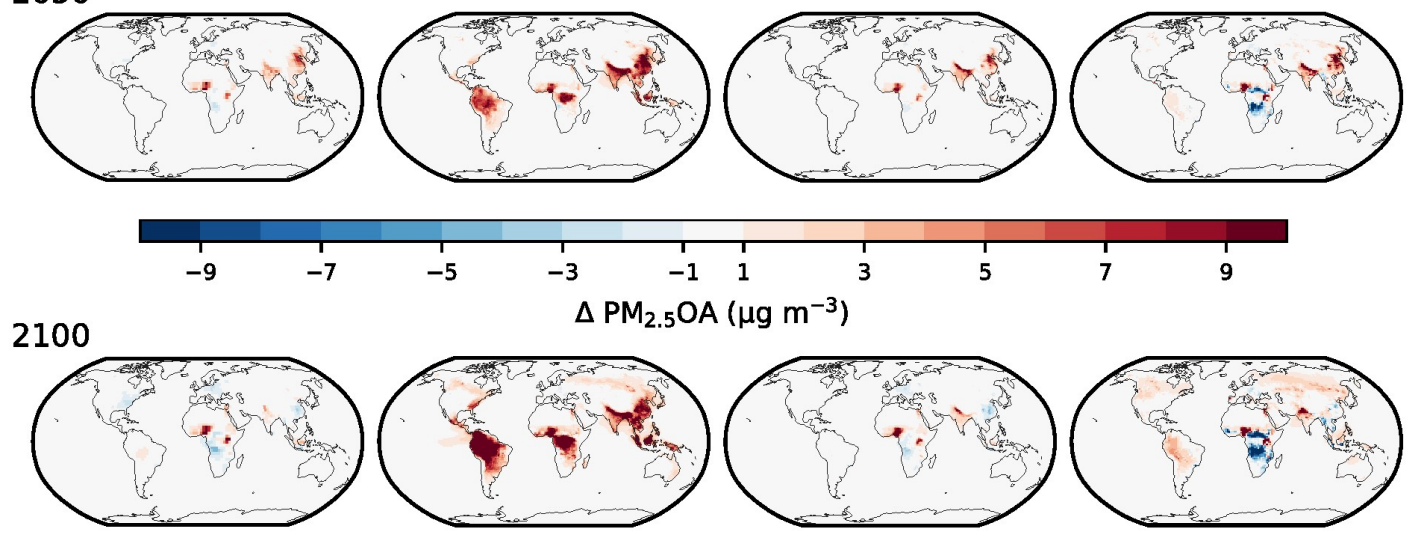

90 Figure S18 - same as Fig S16 but for $\mathbf{P M}_{2.5}$ organic aerosol 

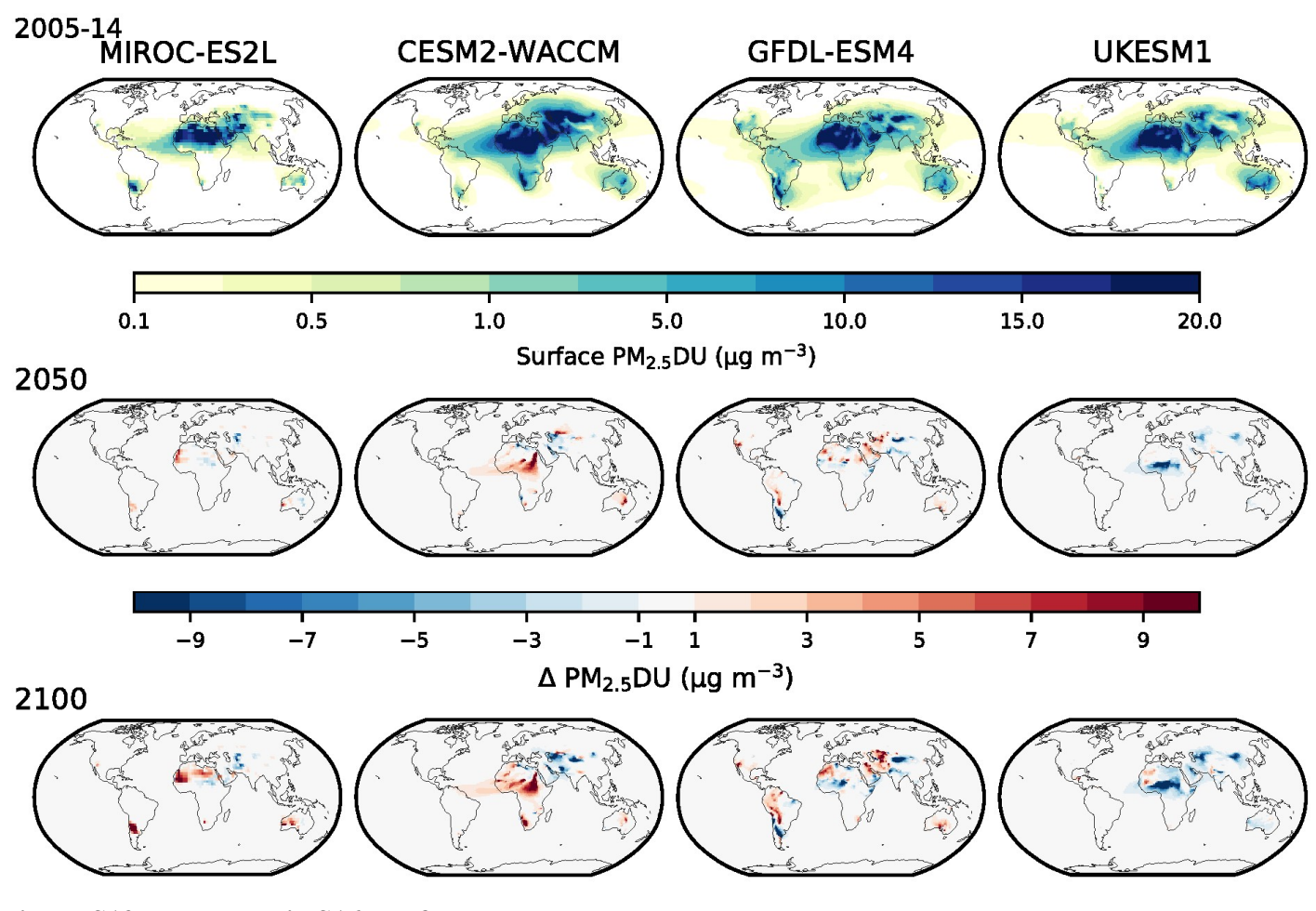

Figure S19 - same as Fig S16 but for PM2.5 dust

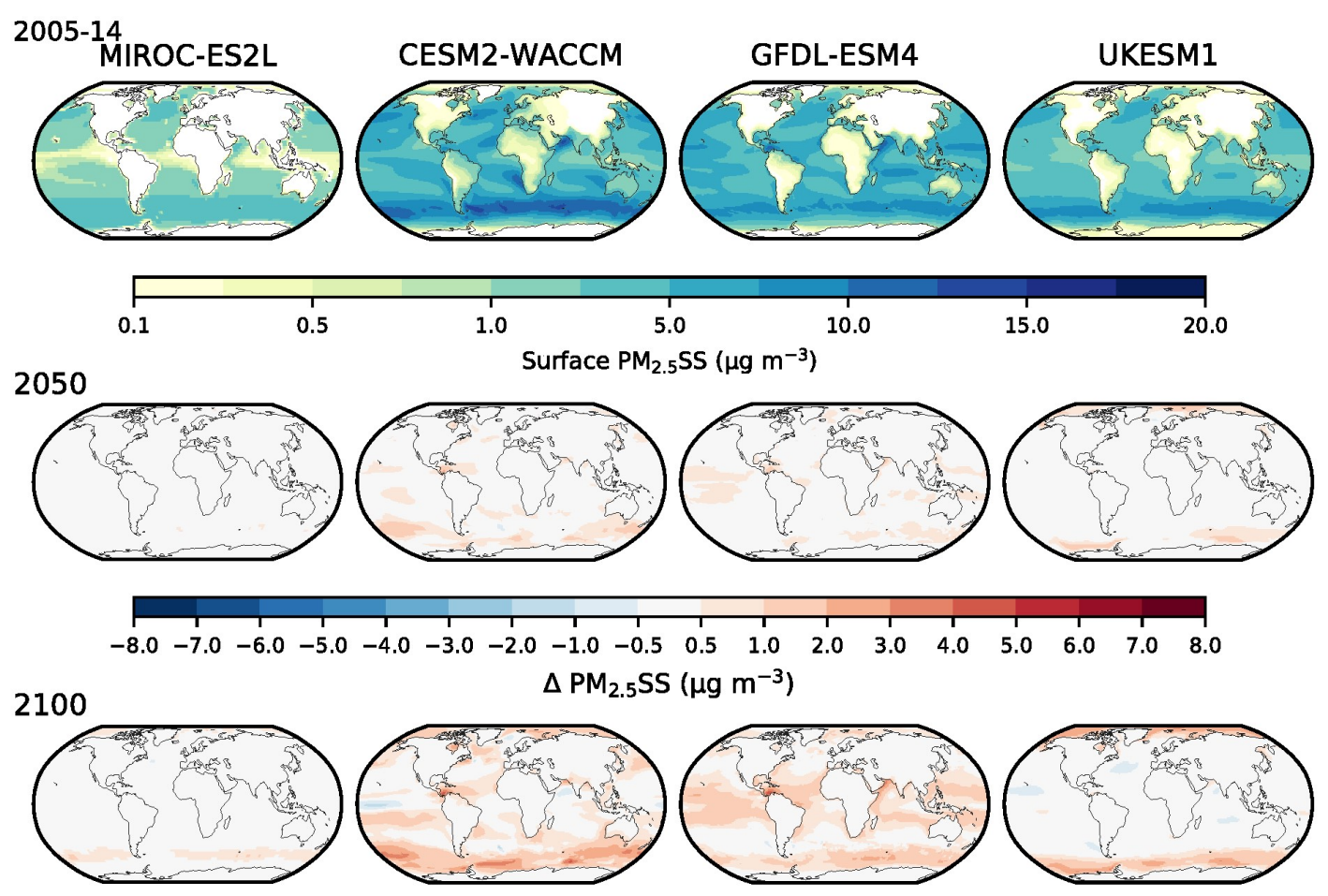

Figure S20 - same as Fig S16 but for $\mathrm{PM}_{2.5}$ sea salt 